\title{
¿SON VÁLIDAS LAS NOTIFICACIONES PRACTICADAS MEDIANTE CORREO ELECTRÓNICO?
}

\author{
JOSÉ IGNACIO CUBERO MARCOS ${ }^{1}$ \\ Universidad del País Vasco/Euskal Herriko Unibertsitatea \\ joseignacio.cubero@ehu.eus
}

Cómo citar/Citation

Cubero Marcos, J. I. (2017).

¿Son válidas las notificaciones practicadas mediante correo electrónico? Revista de Administración Pública, 204, 133-163.

doi: https://doi.org/10.18042/cepc/rap.204.05

\section{Resumen}

El correo electrónico es una herramienta de uso común por las personas que se relacionan o comunican a través de Internet. En las relaciones con la Administración, no obstante, se exige el cumplimiento de determinadas garantías que permitan dejar constancia de la emisión, la recepción y el acceso a las notificaciones, por lo que este medio de notificación solo puede emplearse en tanto en cuanto se alcancen estos fines mediante el uso de los mecanismos técnicos necesarios. Debe plantearse la distinción entre las comunicaciones realizadas por medios electrónicos y las notificaciones realizadas por estos medios, debido a que estas son las que posibilitan el ejercicio de potestades administrativas y los derechos a las personas destinatarias de las mismas. Tal y como está configurado el procedimiento electrónico, han de aplicarse las normas que se derivan del mismo, las cuales no siempre coinciden con aquellas aplicables a las notificaciones en papel.

\section{Palabras clave}

Notificaciones; correo electrónico; procedimiento administrativo; Administración electrónica.

1 Profesor agregado de Derecho Administrativo. Este artículo ha sido elaborado en el marco del grupo consolidado de investigación correspondiente al sistema universitario vasco, para el proyecto «Derecho Administrativo, Medio Ambiente y Ordenación del Territorio y Derechos Humanos», con referencia IT1156-16. 


\begin{abstract}
E-mail is a commonly available tool for people communicating with Public Administration on Internet. However, for the dealings with public authorities, it is necessary to comply with requirements that allow interested people to put the messages on the record, receive notifications and access to them. Thus, Public Administration only can use that mechanism as long as it fulfils some technical requirements. We must raise the difference between communications delivered by electronic means and electronic notifications, because the last ones enable the competent authorities to exercise the powers and the involved people to make effective their rights. As configured the framework on electronic procedure, it is necessary to apply specific regulations, but it does not mean those are always the same rules applying to paperbased notifications.
\end{abstract}

\title{
Keywords
}

Notifications; e-mail; administrative procedure; electronic procedure; electronic Administration. 


\section{SUMARIO}

I. INTRODUCCIÓN. II. LAS NOTIFICACIONES ELECTRÓNICAS Y SU RÉGIMEN JURÍDICO ACTUAL: 1. Planteamiento general y concepto. 2. Las modalidades: acceso a la sede electrónica o al punto general del acceso. 3. La distinción entre la notificación y el aviso. III. LAS NOTIFICACIONES POR CORREO ELECTRÓNICO: 1. La Ley 11/2007, de 22 de junio, de Acceso Electrónico de los Ciudadanos a los Servicios Públicos (LAE) y el Real Decreto 1671/2009, de 6 de noviembre (RAE). 2. La Ley $39 / 2015$, de 1 de octubre, del Procedimiento Administrativo Común de las Administraciones Públicas. 3. Algunas cuestiones controvertidas a la luz de la Sentencia del Tribunal Supremo de 17 de noviembre de 2016: 3.1. El principio finalista prevalece sobre el formalista. 3.2. El principio de buena fe. 3.3. El uso del correo electrónico como medio de notificación. IV. CONCLUSIONES.

\section{INTRODUCCIÓN}

Los avances tecnológicos actuales y el afianzamiento de los procedimientos tramitados a través de vías electrónicas, siquiera a través de la vía legislativa, están planteando cuestiones y controversias de muy diverso tipo, incluso a la luz de la ya derogada, al menos en parte todavía, Ley 11/2007, de 22 de junio, de Acceso Electrónico de los Ciudadanos a los Servicios Públicos. Una de ellas viene referida a un mecanismo tecnológico muy habitual en los quehaceres diarios, cual es el correo electrónico como medio de comunicación entre la Administración y las personas. Así, ¿ puede servir el correo electrónico como medio de comunicación y, por tanto, también como instrumento para emitir, recibir y conocer el contenido de las notificaciones administrativas? La respuesta puede resultar categórica, pero no puede sustraerse a numerosos matices, excepciones, limitaciones o explicaciones.

El derecho administrativo plantea cada día un reto distinto, al superponer y aplicar normas de muy diverso tipo en los diferentes ámbitos institucionales y territoriales que, a su vez, disponen de procedimientos heterogéneos por razón de la materia ${ }^{2}$. Así, aunque las normas comunes sobre procedimiento

2 J. A. Santamaría Pastor (2015), «Los proyectos de Ley del Procedimiento Administrativo Común de las Administraciones Públicas y de Régimen Jurídico del Sector 
administrativo contribuyen en no pocos casos a introducir coherencia y cierta seguridad jurídica, la misma Administración y los tribunales se encargan de confundir en mayor medida a los operadores jurídicos y a las personas en la resolución de controversias. Las notificaciones por vía electrónica requieren un análisis y un examen minucioso que se alejan en muchos casos de las reglas que rigen las notificaciones en papel, por lo que el enfoque debe cambiar respecto a estas últimas ${ }^{3}$. Se trata de abordar cuestiones técnicas, del mundo virtual que representa Internet, de la seguridad en el mismo, de la identificación o de la certificación electrónica ${ }^{4}$.

Lejos de afrontar el análisis desde aquella perspectiva, la reciente sentencia de la Sala $3^{a}$ del Tribunal Supremo, de 17 de noviembre de 2016, ha priorizado la finalidad o el sentido funcional de la notificación sobre su carácter formal, pese a que en las notificaciones electrónicas este último reviste una enorme relevancia, al ser el cauce electrónico la principal nota distintiva respecto a la notificación física en papel, lo que lleva el debate a otros parámetros, más relacionados con la técnica y con elementos todavía desconocidos para el jurista común, pero igualmente válidos, aplicables e imperativos ${ }^{5}$. Este

Público: una primera evaluación», Documentación Administrativa, 2. Acerca de este particular, el autor critica la heterogeneidad y diversidad en las formas de notificación que pueden desembocar en una considerable inseguridad jurídica.

3 E. Gamero Casado (2005), Notificaciones telemáticas, Barcelona: Bosch, in toto.

4 Z. Sánchez Sánchez (2016), «Las nuevas leyes de régimen jurídico y procedimiento administrativo: afianzamiento de la Administración electrónica en las relaciones internas de la Administración y con los ciudadanos», en R. Rivero Ortega (dir.), M. D. Calvo Sánchez y M. M. Fernando Pablo (coords.), Instituciones de procedimiento administrativo común. Novedades de la Ley 39/2015, Lisboa: Juruá Editorial, págs. 117-209. Asimismo, I. Martín Delgado (2016), "La reforma de la Administración electrónica: una panorámica general del impacto de la nueva Ley de Procedimiento Administrativo Común en las relaciones de los ciudadanos con la Administración pública», en F. López Menudo (dir.), Innovaciones en el procedimiento administrativo común y el nuevo régimen jurídico del sector público, Sevilla: Instituto García Oviedo, pág. 50. Asimismo, L. Míguez Macho (2016), «Capítulo 3. La notificación en clave electrónica: análisis del modelo a la luz de las garantías del procedimiento», en C. Campos Acuña (dir.), El nuevo procedimiento administrativo local, Madrid: Wolters Kluwer, pág. 357. M. J. Gallardo Castillo (2016), Los procedimientos administrativos en la Ley 39/2015: análisis y valoración de la reforma, Madrid: Tecnos, págs. 141-147.

5 J. I. Cubero Marcos (2017), Las notificaciones administrativas, Ońati: IVAP, págs. 181 246. En especial lo que se refiere a las notificaciones por correo electrónico (págs. 229-234). Un análisis interesante lo proporciona J. Fondevila Antolín (2016), «Una aproximación al nuevo régimen jurídico de las notificaciones administrativas en la Ley 39/2015", Actualidad Administrativa, 2. 
trabajo tiene por objeto poner de manifiesto en qué medida el medio, la vía o el cauce de la notificación electrónica adquiere igual o mayor importancia que su finalidad, dado que en el fondo ambas cuestiones, lo formal y lo material en las notificaciones electrónicas, requieren una mayor interacción, como si fueran dos caras de la misma moneda ${ }^{6}$. La notificación practicada por correo electrónico representa un paradigma de esta teoría. Asimismo, se ha tomado como objeto de análisis, reflexión y crítica la sentencia mencionada anteriormente, pues refleja todavía hoy las dificultades que entraña abordar controversias vinculadas a la Administración electrónica.

\section{LAS NOTIFICACIONES ELECTRÓNICAS Y SU RÉGIMEN JURÍDICO ACTUAL}

\section{PLANTEAMIENTO GENERAL Y CONCEPTO}

Frente a las notificaciones practicadas en papel o por medios ordinarios, las electrónicas se efectúan por medios telemáticos, lo que significa que su contenido se transmite a través de Internet mediante los dispositivos habilitados para ello y empleando las herramientas tecnológicas necesarias, especialmente el software, es decir, los programas informáticos, así como los sistemas operativos compatibles que permitan la interoperabilidad entre los aparatos del emisor y el receptor ${ }^{7}$. Sin perjuicio de advertir que tanto los documentos enviados como los mensajes se encuentran digitalizados, la forma o el cauce de emisión y recepción de la notificación depende de un mecanismo tecnológico alejado de una realidad física, y que emplea un lenguaje digital para reconocer, transportar y certificar la existencia de una notificación ${ }^{8}$. En consecuencia, el régimen jurídico entre unas y otras varía, tal y como habrá ocasión de examinar a continuación?.

Para entender válidamente practicada una notificación electrónica, se precisa que la Administración disponga de los mecanismos técnicos necesarios que permitan certificar y verificar que las comunicaciones realizadas se

6 F. Álvarez García (2016), «Notificación y avisos electrónicos: ventajas y dificultades», El Consultor de los Ayuntamientos, 8, págs. 897-303.

7 E. Gamero Casado (2010), «Comunicaciones y notificaciones electrónicas», Cuadernos de Derecho Local, 22, págs. 102 y ss.

8 R. Martínez Gutiérrez (2009), Administración pública electrónica, Madrid: CivitasThomson Reuters, págs. 540-543.

9 F. J. Bauzá Martorell (2003), «Notificaciones en soporte magnético», RAP, 161, pág. 181 . 
han originado, que proceden de sus autores y no de personas ajenas, y que han sido recibidas a una fecha y hora determinada ${ }^{10}$. Todas estas herramientas de software y de seguridad sustituyen a la presencia física en las dependencias administrativas o a la firma que debe figurar en el acuse de recibo. Por tanto, resulta indispensable que la Administración emplee estos mecanismos de certificación y que cuenten con las máximas garantías de seguridad ${ }^{11}$. Así, si el lenguaje de unos y ceros y la conexión entre dispositivos remotos trata de reemplazar la notificación ordinaria inmediata en papel, todos ellos, al menos, deben disponer de garantías suficientes y con un menor margen de error para constatar el acto de la notificación, su recepción, autoría y contenido ${ }^{12}$.

Más allá del derecho que les asiste a las personas interesadas de tramitar el procedimiento por vías electrónicas y la obligación que pesa sobre la Administración para satisfacerlo, no todas ellas se encuentran constreñidas al empleo de medios electrónicos en los procedimientos ${ }^{13}$. De momento, el deber de comunicarse con la Administración por estos medios se ha impuesto a colectivos muy específicos $y$, salvo procedimientos concretos que requieran una tramitación más ágil, lo cierto es que los expedientes ordinarios no deberían desaparecer y debería permitirse que aquellas opten por el que les resulte más propicio a sus intereses ${ }^{14}$. Sin entrar en más detalles, llama la atención, de

10 Gamero Casado (2010: 98 y 99). Asimismo, J. Valero Torrijos (2007), El régimen jurídico de la e-Administración. El uso de medios informáticos y telemáticos en el Procedimiento Administrativo común, Granada: Comares, in toto. J. L. Piñar Mañas (2011), «Revolución tecnológica y nueva Administración», en J. L. Piñar Mañas (dir.), Administración electrónica y ciudadanos, Cizur Menor: Thomson Reuters-Civitas, págs. 33-39.

11 E. Gómez-Reino y Carnota (2015), «Las notificaciones electrónicas», en M. Rebollo Puig, M. López- Benítez y E. Carbonell Porras (coords.), Régimen jurídico básico de las administraciones públicas. Libro homenaje al profesor Luis Cosculluela, Madrid: Iustel, pág. 419.

12 Gamero Casado (2010: 102).

13 Art. 14.1 LPAC.

14 STSJ Madrid, 14 de julio de 2016, JT/2016/1210, FD $4^{\circ}$. En el caso de los obligados tributarios, el mismo RD 1613/2010, de 29 de octubre, ya establecía la obligatoriedad de comunicarse por medios electrónicos con la Administración por parte de determinados colectivos. J. Valero Torrijos (2010), «El alcance de la protección constitucional del ciudadano frente al uso de medios electrónicos por la Administración», en L. Cotino Hueso y J. Valero Torrijos (coords.), Administración electrónica. La Ley 11/2007, de 22 de junio, de Acceso electrónico de los ciudadanos a los servicios públicos y los retos jurídicos del e-gobierno en España, Valencia: Tirant lo Blanch, pág. 143. Asimismo, véase L. Cotino Hueso (2010), «El derecho a relacionarse electrónicamente con las administraciones y el estatuto del ciudadano e-administrado en la Ley 11/2007 y la 
todos modos, que el régimen de las notificaciones, sean procedimientos ordinarios o electrónicos, varíe sustancialmente y que el legislador para estos últimos no haya adoptado medidas que se ajusten a la doctrina del TC respecto a la diligencia exigible en materia de notificaciones. Así, se pone de manifiesto, por ejemplo, en la presunción de notificación por el transcurso del tiempo que ya preveía la Ley 11/2007, de Acceso Electrónico de los Ciudadanos a los Servicios Públicos (LAE) ${ }^{15}$ y que ahora se ha respaldado en la LPAC.

La doctrina ha mostrado especial preocupación por la proliferación de procedimientos electrónicos sin tener en cuenta el principio de proporcionalidad $^{16}$. La misma LPAC, siguiendo la estela de la LAE, permitió al gobierno ampliar los supuestos en que se obligaba a la tramitación electrónica, y la jurisprudencia en el caso de los procedimientos tributarios sostuvo su conformidad a derecho porque se respetaban los requisitos de disponibilidad técnica, económica y tecnológica para el acceso ${ }^{17}$. Sin embargo, ese fallo fue objeto de crítica por un voto particular que recalcó la necesidad de que el Reglamento tuviera en cuenta las circunstancias particulares de cada sujeto

normativa de desarrollo», en E. Gamero Casado y J. Valero Torrijos (coords.), La Ley de Administración electrónica. Comentario sistemático a la Ley 11/2007, de 22 de junio, de Acceso electrónico de los ciudadanos a los servicios públicos, Madrid: AranzadiThomson Reuters, $3^{\mathrm{a}}$ ed., pág. 182.

15 Al respecto, véase N. Álamo González (2007), «La utilización de las nuevas tecnologías en las relaciones entre las administraciones públicas y los ciudadanos (en particular, Registros telemáticos y notificaciones telemáticas): hacia un cambio de modelo», REDA, 133, págs. 89-133.

16 Al respecto, véase SAN, 16 de febrero de 2015. Valida la Orden HAP/2194/2013, de 22 de noviembre, por la que se regulan los procedimientos y las condiciones generales para la presentación de determinadas autoliquidaciones y declaraciones informativas de naturaleza tributaria. Considera que el colectivo de abogados ejercientes cumple los requisitos de capacidad técnica, económica o dedicación profesional. J. Valero Torrijos (2007), Régimen jurídico de la e-Administración. El uso de medios informáticos y telemáticos en el procedimiento administrativo común, Granada: Comares, pág. 48. Véase también E. M. Menéndez Sebastián (2016), «La implementación de la Administración electrónica en las nuevas leyes», El Cronista del Estado Social y Democrático de Derecho, 63, pág. 30.

17 STS 22 de febrero de 2012, RA 4897, FD 7o y 8º. El Tribunal declaró que la obligación de comunicarse con la Administración por medios electrónicos se derivaba de una norma reglamentaria cuya habilitación había sido prevista por el art. 27.6 LAE, y que los requisitos de disponibilidad técnica, económica y tecnológica para el acceso se cumplían para los obligados tributarios en este caso. Véase al respecto también J. M. Baño León (2015), «La reforma del procedimiento. Viejos problemas no resueltos y nuevos problemas no tratados», Documentación Administrativa, 2. 
obligado, sin que pueda establecerse una generalización para determinados tipos de sujetos que no se ajustan a los criterios de disponibilidad y acceso que prevé expresamente la Ley ${ }^{18}$. Del mismo modo, las críticas doctrinales se han ido sucediendo, bien por la imposibilidad de que se imponga la obligación en sede reglamentaria ${ }^{19}$, bien por la enorme incidencia que el tránsito hacia las notificaciones electrónicas podía tener en el ejercicio del derecho a la tutela judicial efectiva ${ }^{20}$.

La notificación surte sus efectos desde el momento en que la persona interesada accede al contenido de la misma, cuestión que ha de acreditarse mediante los instrumentos tecnológicos, software, programas o sistemas de seguridad previamente certificados ${ }^{21}$. Antes de que se conozca el contenido de la

18 En concreto, el voto particular se expresó del siguiente modo: «[...] La opinión mayoritaria al considerar que la naturaleza de los destinatarios excluye apriorísticamente la aplicabilidad de las limitaciones establecidas en la ley a los destinatarios de las notificaciones, y sin tener en cuenta las circunstancias de cada caso concretas, la posible carencia de medios tecnológicos para una adecuada recepción de las notificaciones electrónicas, da cobertura a una disposición que, en mi opinión, carece de ella». Respecto al sentido de la proporcionalidad para obligar al empleo de medios electrónicos en las comunicaciones con la Administración, puede verse A. Boix Palop (2010), «Previsiones en materia de neutralidad tecnológica y acceso a los servicios de la Administración», en L. Cotino Hueso y J. Valero Torrijos (coords.), Administración..., cit., págs. 308 y 309. Al respecto, véase también la crítica que realiza el Consejo de Estado, que declaró expresamente que los sujetos que están obligados a comunicarse por vías electrónicas con la Administración se han fijado sin tener en cuenta la realidad operativa de muchas sociedades. Dictamen del Consejo de Estado sobre el Anteproyecto de Ley del Procedimiento Administrativo Común, de 29 de abril de 2015, expediente 275/2015, pág. III B).4.

19 R. Falcón y Tella (2011), «La dudosa constitucionalidad del sistema de notificaciones electrónicas en su actual configuración", Revista Quincena Fiscal, 17.

20 T. R. Fernández Rodríguez (2015), «Una llamada de atención sobre la regulación de las notificaciones electrónicas en la novísima Ley de Procedimiento Administrativo Común de las administraciones públicas», RAP, 198, págs. 362-369. La determinación de lo que se considera medios disponibles conforme a la capacidad económica o técnica de los colectivos sociales está más allá de lo que una norma reglamentaria puede hacer, al margen de que la carga económica de relacionarse con la Administración recaerá sobre la ciudadanía.

21 I. Martín Delgado (2017), «Ejecutividad y eficacia de los actos administrativos. Las notificaciones administrativas», en E. Gamero Casado y S. Fernández Ramos (dirs.) y J. Valero Torrijos (coord.), Tratado de Procedimiento Administrativo común y régimen jurídico básico del sector público, Valencia: Tirant lo Blanch, pág. 2145. El autor distingue acertadamente entre el sistema de notificación y la elección del medio, pues 
notificación, la Administración ha de garantizar que la ha puesto a disposición de la persona interesada en una fecha y hora determinadas. Todo ello comporta la presunción de que tanto la Administración como la persona destinataria del acto disponen de los medios, dispositivos, programas y aplicaciones necesarios, no solo para la conexión y la interoperabilidad, sino también para que la comunicación pueda entenderse, descargarse y usarse de una forma que no pueda diferir de la que se emplea para las notificaciones en papel. Una de las novedades de la LPAC se refiere al hecho de que, pese a que la persona interesada no haya manifestado expresamente que prefiere tramitar el procedimiento por vías telemáticas, puede acceder a la notificación previa recepción del aviso correspondiente. Eso no puede significar, en cualquier caso, que aquella haya renunciado al procedimiento ordinario en papel, aunque puede servir para demostrar que ha recibido la notificación.

\section{LAS MODALIDADES: ACCESO A LA SEDE ELECTRÓNICA O AL PUNTO GENERAL DEL ACCESO}

En la actualidad, la notificación electrónica debe practicarse por comparecencia en la sede electrónica o accediendo a la dirección electrónica única, o a través de ambos mecanismos. La primera implica que el interesado debe identificarse para acceder a la plataforma donde puede recibir las notificaciones y avisos ${ }^{22}$. Así, el interesado o su representante, debidamente identificados, pueden acceder al contenido de la notificación ${ }^{23}$. La aplicación electróni$\mathrm{ca}$, asimismo, ha de constatar que el interesado ha tenido acceso al expediente administrativo y a la notificación en cuestión ${ }^{24}$. Se ha afirmado que el legislador ha confundido portal con sede electrónica, porque dentro del portal se encuentra la sede electrónica que es el sitio web al que debe conectarse la persona interesada ${ }^{25}$. Con anterioridad, tal y como se comentará infra, aquella

corresponde a la Administración la habilitación de concretos sistemas de notificación electrónica.

22 Art. 43.1 LPAC.

23 I. Martín Delgado (2010), «Concepto y régimen jurídico de la sede (administrativa) electrónica», en L. Cotino Hueso y J. Valero Torrijos (coords.), Administración..., cit., pág. 504.

24 A. Cerrillo (2008), e-Administración, Barcelona: UOC, pág. 68. La sede electrónica es un conjunto de páginas web agrupadas en un dominio de Internet cuyo objetivo es ofrecer al usuario el acceso a una serie de recursos dirigidos a resolver necesidades específicas y debe crearse mediante un acto formal que debe ser publicado, en el que se determinan sus características.

J. Valero Torrijos (2010: 348 y 349). 
debe recibir un aviso de notificación en los diferentes dispositivos habilitados al efecto, que haya indicado previamente en la solicitud o que figuren en el expediente ${ }^{26}$. Esta comparecencia también puede efectuarse desde el Punto de Acceso General Electrónico de la Administración, sin olvidar el deber de asistencia que ha de brindar toda Administración pública para el uso de las herramientas electrónicas ${ }^{27}$, debido a que, en muchos casos, las cargas que recaen sobre la ciudadanía son excesivas o desproporcionadas para mantener actualizados sistemas operativos o determinado software necesario para operar con seguridad ${ }^{28}$.

La otra forma de practicar la notificación consiste en la puesta a disposición del documento electrónico en la dirección electrónica habilitada por la Administración ${ }^{29}$. Este tipo de notificaciones resulta válido si permite acreditar la fecha y la hora en que se produce la puesta a disposición del interesado del acto objeto de notificación. En caso de que se facilite el acceso permanente a la dirección electrónica correspondiente, a través de una sede electrónica o de cualquier otro modo, debe acreditarse la fecha y la hora del acceso al contenido de la notificación y, por último, han de existir mecanismos de autenticación para garantizar la exclusividad del uso y la identidad del usuario ${ }^{30}$. Las personas pueden solicitar a la Administración la apertura de esta dirección electrónica, que tendrá vigencia indefinida, excepto en los supuestos en que se solicite su revocación por el titular ${ }^{31}$. Todos estos requisitos, previstos en el Real Decreto 1671/2009 (RAE), por el que se desarrolla la Ley 11/2007, de Acceso Electrónico de los Ciudadanos a los Servicios Públicos, todavía resultan aplicables hasta la entrada en vigor definitiva de la LPAC el 2 de octubre

26 R. Martínez Gutiérrez (2016), El régimen jurídico del nuevo procedimiento administrativo común, Cizur Menor: Thomson Reuters-Aranzadi, pág. 189.

27 Véase el art. 53.1 LPAC. El derecho a realizar copias se entenderá satisfecho con la puesta a disposición de las mismas en el Punto de Acceso General Electrónico de las Administración competente o en las sedes electrónicas que correspondan.

28 A. Díaz-Romeral (2011), «La sede electrónica: eje vertebrador del derecho de los ciudadanos a la información, a la participación y a relacionarse por medios electrónicos con las administraciones públicas», en J. L. Piñar Mañas (dir.), Administración electrónica..., cit., 2011, pág. 404. Véase también V. Magro Servet (2013), «El domicilio electrónico como garantía de la agilización de los actos de comunicación entre la Administración pública y los ciudadanos», Diario la Ley, 8131, véase en www.laley.es. Martín Delgado (2017: 2144). Especialmente el acceso a las notificaciones en procedimientos iniciados de oficio puede efectuarse a través de la dirección electrónica habilitada única.

30 Arts. 38.1 y 2 RAE.

31 Álvarez García (2016: 905). 
de 2018, en el que se habrá implantado el modelo de Administración electrónica $^{32}$. En este caso, no se exige la firma de la notificación por vías electrónicas, sino que únicamente el interesado debe identificarse para el acceso a la sede electrónica, donde puede acceder al contenido de la notificación ${ }^{33}$. Tanto la notificación por dirección electrónica habilitada como aquella que se efectúa por comparecencia en la sede electrónica son compatibles y pueden realizarse al mismo tiempo.

$\mathrm{Al}$ respecto, ha de notarse aquí la importancia de la regulación relativa a los documentos electrónicos, no solo por la necesidad de que sean inteligibles, sino porque resulta indispensable que el sistema genere la correspondiente copia electrónica una vez que se facilita el acceso a ellos ${ }^{34}$. Asimismo, la interoperabilidad de los sistemas probablemente se convertirá en el mayor reto que debe afrontar la Administración electrónica, debido a que se trata del principio que permite sustituir lo físico por lo virtual ${ }^{35}$. Así, la Administración debería remover todos los obstáculos o barreras que impidan la comunicación efectiva con la ciudadanía ${ }^{36}$, lo que significa que, más allá de habilitar la asistencia técnica necesaria a través de los funcionarios habilitados al efecto para la firma electrónica, han de poner a disposición de aquella los canales de acceso que sean necesarios, así como los sistemas y aplicaciones que en cada caso se determinen ${ }^{37}$.

32 J. Rodrigo Fernández (2016), «Las notificaciones electrónicas obligatorias tributarias: balance de la situación ante la Ley 34/2015, de 21 de septiembre, de modificación parcial de la LGT», Carta Tributaria. Revista de Opinión, 13.

33 Menéndez Sebastián (2016: 33).

34 F. J. Sanz Larruga (2010), «Documentos y archivos electrónicos», en E. Gamero Casado y J. Valero Torrijos (coords.), La Ley de Administración ..., cit., pág. 703. Asimismo, A. Palomar Olmeda (2009), «Procedimientos administrativos y régimen documental en la actuación de la Agencia Española de Protección de Datos», VV.AA., Protección de datos en la Administración electrónica, Cizur Menor: Thomson Reuters-Aranzadi, págs. 88-89. J. M. Álvarez-Cienfuegos Suárez (2001), "La nueva Administración electrónica y las notificaciones efectuadas por medios telemáticos», Revista Jurídica Navarra, 32, pág. 85 .

35 L. Davara Fernández de Marcos y M. A. Davara Rodríguez (2016), «La Administración electrónica en la Ley 39/2015 de Reforma de la Ley de Régimen Jurídico de las Administraciones Públicas y del Procedimiento Administrativo Común», Actualidad administrativa.

36 V. Manteca Valdelande (2013), "Comunicaciones de actos administrativos y disposiciones de carácter general (3)", Actualidad Administrativa, 4, véase en www.laley.es.

37 Art. 12 LPAC. A. B. Casares Marcos (2016), «Novedades en materia de Administración electrónica en la nueva legislación administrativa básica», Revista Jurídica de Castilla y León, 40, pág. 16. Martínez Gutiérrez (2016: 222). 


\section{LA DISTINCIÓN ENTRE LA NOTIFICACIÓN Y EL AVISO}

El aviso de notificación debe ser enviado a la dirección de correo electrónico del interesado o a cualquier dispositivo electrónico, informándole de la puesta a disposición de una notificación en la sede electrónica de la Administración u organismo correspondiente, o en la dirección electrónica habilitada única ${ }^{38}$. Aun así, si no se produce el aviso, la notificación puede ser considerada válida. Este aviso debe distinguirse de la notificación en sí, ya que únicamente se le advierte al interesado de que aquella se encuentra a su disposición ${ }^{39}$. Aunque no incide en la validez de la notificación, no puede afirmarse que carezca de efectos. Por un lado, si se acredita que se ha producido el aviso, puede entenderse que la Administración ha cumplido su deber de notificar de forma diligente a la persona interesada, lo que le ahorra muchos trámites y tiempo para tratar de localizarla ${ }^{40}$.

Por otro lado, el aviso no puede calificarse como la puesta a disposición de la notificación, como si se tratara de un procedimiento o notificación electrónica ${ }^{41}$. Eso significa que, pese a que ha existido el aviso, no puede afirmarse que la persona interesada esté en condiciones de acceder a la notificación. Así, no puede albergar otros efectos distintos a los meramente informativos ${ }^{42}$. Piénsese que la notificación se ha depositado en la sede electrónica o en la dirección electrónica habilitada única y que el interesado puede no haber elegido la vía telemática porque no conoce bien el funcionamiento y probablemente también ignora la posibilidad de acudir a una oficina administrativa para ser asistido ${ }^{43}$. No todas las personas disponen de conexión a Internet ni de los dispositivos electrónicos necesarios para acceder a los expedientes o procedimientos electrónicos o los programas o aplicaciones para ello.

El aviso de notificación puede emplearse como una prueba para acreditar la falta de diligencia o la mala fe de la persona interesada, pero para ello debe probarse el envío, la emisión y la recepción del mensaje a través de los medios o dispositivos. Esta cuestión ha sido abordada por la jurisprudencia en relación al material probatorio objeto de examen por los tribunales penales, por ejemplo ${ }^{44}$.

\footnotetext{
Art. 41.6 LPAC.

39 Álvarez García (2016: 900-903).

40 Fondevila Antolín (2016).

41 Cubero Marcos (2017: 89 y 90).

42 Rodrigo Fernández (2016).

43 Martín Delgado (2017: 2168). Pone de manifiesto la necesidad de que el interesado se exprese claramente en torno al medio por el que se practica la notificación.

44 Pueden citarse diferentes resoluciones judiciales, como la STS (Sala de lo Penal) de 30 de enero de 2014, FD $2^{\circ}$. Se trata de la interceptación del IP correspondiente a un
} 
Aun así, desde la doctrina se ha señalado que el hecho de efectuar avisos no puede convertir un procedimiento que se lleva a cabo en papel, por los medios ordinarios, en uno electrónico con sus correspondientes automatismos ${ }^{45}$. En ese sentido, pese a que se ha efectuado el aviso, todavía recae sobre la Administración la carga de la prueba en torno a la práctica de la notificación, de modo que despeje toda duda acerca de la mala fe, falta de diligencia del destinatario $\mathrm{o}$, incluso, el cumplimiento de las formalidades correspondientes por parte de aquella. Desde otra perspectiva doctrinal se ha puesto el acento en el aviso como un mecanismo para evitar la indefensión, pese a que esta misma determinaría la invalidez del acto, al afectar al art. 24.1 $\mathrm{CE}^{46}$.

Una vez recibido el aviso, el acceso a la notificación a través de la sede electrónica o la dirección electrónica habilitada única no conlleva de por sí que el interesado haya de tramitar el procedimiento electrónico ni que las

coimputado que declara en contra de otras personas que han participado en el ilícito penal. Se comprueba a través de Microsoft, como la compañía que presta el servicio de almacenamiento de los mensajes, que, efectivamente, los mismos habían sido conocidos y emitidos por las personas imputadas. Más allá de que no se vulnera el derecho a la intimidad y al secreto de las comunicaciones, se logra destruir la presunción de inocencia mediante la exposición de los materiales probatorios, concediendo la correspondiente contradicción en la vía del juicio oral. En concreto, se presentó como prueba el hecho de que los presuntos autores frecuentaban un cibercafé desde el que enviaban y recibían los mensajes. Esta circunstancia no fue acreditada y de ahí que la prueba careciera de virtualidad. STS (Sala de lo Penal) de 26 de mayo de 2015, RA 2475 , FD 20. Las grabaciones de vídeos pornográficos enviados por Whatsapp permitieron corroborar algunos testimonios y considerar esas pruebas como incriminatorias o de cargo. Véase asimismo SAP Madrid (Sala de lo Penal), de 5 de abril de 2013, JUR/2013/175198, FD 5․ Se reproducen las conversaciones mantenidas por este medio en un asunto relacionado con la violencia doméstica y que hacían referencia al testimonio de la víctima contado a una amiga suya, pese a que los hechos no fueron denunciados de manera inminente. Asimismo, véanse SAP Ciudad Real (Sección 1a de lo Penal), de 24 de febrero de 2015, FD 1\%; Valladolid, de 13 de abril de 2015, JUR/2015/124524, FD 1o; y SAP Madrid 12 de enero de 2015, JUR/2015/72795, FD $3^{\circ}$.

45 I. Martín Delgado, (2016) «El impacto de la reforma de la Administración electrónica sobre los derechos de los ciudadanos y el funcionamiento de las administraciones públicas», en M. Almeida Cerreda y L. Míguez Macho (dirs.), La actualización de la Administración electrónica, Santiago de Compostela: Andavira, pág. 60. Se establece la obligación del interesado, aunque sea de forma encubierta, de acceder a las sedes electrónicas o a su dirección electrónica habilitada única en muy corto espacio de tiempo para saber si dispone de la notificación.

46 Martín Delgado (2017: 2164). 
siguientes notificaciones hayan de recibirse por vías telemáticas, salvo que así expresamente lo manifieste y de ello tenga constancia la Administración ${ }^{47}$. Si el procedimiento se sustanciaba en papel, el principio de voluntariedad rige en todo caso, por lo que, más allá de que la persona interesada haya tenido conocimiento de esa concreta notificación, ha de presumirse que aquella todavía prefiere la vía ordinaria en papel, salvo declaración expresa en contra ${ }^{48}$. De todos modos, en caso de que se haya accedido a la notificación a través de la comparecencia en sede electrónica y el procedimiento se haya sustanciado en papel, se plantea la duda acerca de si la Administración debe cumplir las formalidades y los intentos que prevé la LPAC para las notificaciones practicadas por ese medio ${ }^{49}$. El principio de buena fe y su interpretación caso por caso por los tribunales puede despejar esta incógnita en el futuro, lo que, no obstante, supone una amplia dosis de inseguridad jurídica acerca de qué normativa rige, la de las notificaciones electrónicas o aquella que se lleva a cabo en papel ${ }^{50}$.

\section{LAS NOTIFICACIONES POR CORREO ELECTRÓNICO}

El correo electrónico podría servir como mecanismo técnico adecuado para la emisión, puesta a disposición y recepción de las notificaciones, siempre

47 Gallardo Castillo (2016: 169). La opción preferida por el interesado debe interpretarse como una manera de facilitar la realización del trámite a la Administración, pero no tiene efectos vinculantes ni imperativos para ella. Valero Torrijos (2007: 140). Se pronuncia favorablemente al consentimiento expreso.

M. D. Rego Blanco (2010), «Registros, comunicaciones y notificaciones electrónicas», en E. Gamero Casado y J. Valero Torrijos (coords.), La Ley de Administración..., cit., págs. 535-542. J. A. Hernández Corchete (2011), «El derecho de los ciudadanos a relacionarse con las administraciones públicas utilizando medios electrónicos y los derechos complementarios que delimitan su alcance», en J. L. Piñar Mañas (dir.), Administración electrónica..., cit., págs. 121-125.

49 STSJ Madrid 22 de septiembre de 2014, RA RJCA/2014/1008, FD 4o. Al no consultarse el correo electrónico que se había señalado a efectos de notificaciones, no se pudo subsanar la solicitud de inscripción en el registro de preasignación de retribución para instalaciones fotovoltaicas. La cuestión en este caso radicaba en que efectivamente la norma del procedimiento exigía la notificación o comunicación por vías electrónicas.

50 E. García de Enterría y T. R. Fernández Rodríguez (2015), Curso de Derecho Administrativo, Cizur Menor: Thomson-Reuters, 17a edic., pág. 626. Los autores entienden que la notificación se presentaba hasta ahora como una pesada carga que recaía sobre la Administración si quería que sus actos produjesen efectos. La carga cambia de sentido en la actualidad, toda vez que el interesado es el que deberá acudir al domicilio electrónico de la Administración. 
que reúna los requisitos y características técnicas que se señalaron con anterioridad y que permita certificar la autoría de la emisión, las fechas y horas de la puesta a disposición y de la recepción ${ }^{51}$. Esto último se ha perfilado como el gran escollo a salvar para los partidarios del correo electrónico como medio de notificación al uso, cuando se trate de procedimientos electrónicos. Por ello, pese a que en un principio la LAE y su Reglamento parecían admitir esta modalidad técnica, la actual LPAC no lo ha incluido como mecanismo para practicar las notificaciones, probablemente por la heterogeneidad de servidores que ofrecen servicios de correo, con sus propios sistemas de certificación de fechas, horas, o por el diferente modo de funcionar de programas y aplicaciones de correo cuyos comandos no siempre disponen de mecanismos que garanticen la emisión, recepción y puesta a disposición, al margen del necesario acuse de recibo ${ }^{52}$. En cualquier caso, se analizan a continuación todas estas cuestiones para arrojar luz en torno a este medio electrónico para practicar las notificaciones y se concluye abordando el estudio de una interesante y reciente y controvertida sentencia del Tribunal Supremo que resuelve un recurso de casación para la unificación de doctrina.

\section{LA LEY $11 / 2007$, DE 22 DE JUNIO, DE ACCESO ELECTRÓNICO DE LOS CIUDADANOS A LOS SERVICIOS PÚBLICOS (LAE) Y EL REAL DECRETO 1671/2009, DE 6 DE NOVIEMBRE (RAE)}

La LAE establecía el deber de habilitar, en cada una de las sedes electrónicas, sistemas que permitieran el establecimiento de comunicaciones seguras siempre que fueran necesarias. A partir de ahí, el correo electrónico podía insertarse como mecanismo de comunicación seguro ubicado en la sede electrónica ${ }^{53}$. Asimismo, se consideraban válidas las comunicaciones a través de medios electrónicos siempre que existiera constancia de la transmisión y recepción, de sus fechas, del contenido íntegro de las comunicaciones y se identificase fidedignamente al remitente y al destinatario de las mismas ${ }^{54}$. De conformidad con el RAE, el uso del correo electrónico se permitía como medio para practicar notificaciones, siempre que se generase automáticamente,

51 Gamero Casado (2005: 181). Las trazas del envío solo pueden certificarse por el administrador en los tramos adscritos a su competencia. El resto no es susceptible de control y acreditación por la Administración.

52 E. Gamero Casado, (2005), «El correo electrónico como medio de notificación administrativa en el Derecho propio de Andalucía», Administración de Andalucía, Revista Andaluza de Derecho Administrativo, 57, pág. 115.

53 Art. 10.4 LAE. Véase Martín Delgado (2009: 94).

54 Art. 27.3 LAE. 
y con independencia de la voluntad del destinatario, un acuse de recibo que dejara la constancia de su recepción y que se originara en el momento del acceso al contenido de la notificación ${ }^{55}$. Estas previsiones han quedado derogadas de acuerdo con la Disposición Derogatoria Única de la LPAC, al no referirse a materias como el registro electrónico, el archivo electrónico o el punto de acceso electrónico general ${ }^{56}$. Aun así, como se ha podido comprobar en la jurisprudencia, algunas normas, incluso de rango reglamentario y con amparo en el art. 27.3 LAE, han posibilitado recibir notificaciones por correo electrónico como cauce habitual ${ }^{57}$.

La utilización del correo ha contado en la doctrina con partidarios y detractores. Los primeros han abogado por la posibilidad de que se inserte esta función en el mismo servidor en que se ubica la sede electrónica, de modo que los servidores o programas no necesariamente pueden diferir y, de este modo, se incremente el nivel de seguridad y autenticidad de los mensajes ${ }^{58}$. Así, algún autor se inclina por emplear medios telemáticos de este tipo porque disponen de la suficiente eficacia y practicidad para el envío y recepción de mensajes al instante, junto con otras herramientas, como el chat o la videoconferencia ${ }^{59}$. Así, según estas tesis, el correo electrónico con acuse de recibo puede garantizar la certeza del origen y el destino del mensaje, siempre que se genere de modo automático y disponga de los mecanismos técnicos necesarios para acreditar la fecha, hora y sujetos que emiten y reciben la comunicación mediante protocolos que garanticen

55 Art. 35.2 RAE.

56 Gómez-Reino y Carnota (2015: 424).

57 STSJ Madrid 22 de septiembre de 2014, RJCA 2014/1008, FD 4º Se había acreditado la emisión y puesta a disposición de la notificación en una dirección de correo habilitada al efecto, en tanto que el RD 1578/2008, de 26 de septiembre obligaba a emplear la vía electrónica en las relaciones con la Administración.

Manteca Valdelande (2008, III). Dispone de un mecanismo de alta fiabilidad para la actividad que hayan de desarrollar las administraciones públicas en sus relaciones con los ciudadanos. La adopción de estas normas no solo permite la constancia automática de que el mensaje ha sido depositado en el buzón de destino, sino también del momento en que dicho mensaje haya sido abierto, para lo cual remite a los interesados las correspondientes notificaciones de entrega y acuses de recibo, que serán incorporadas al expediente administrativo como prueba válida de que la notificación ha sido practicada. Magro Servet (2013) sostiene lo siguiente: «Además, tenemos la opción ahora de añadir la WebCam al ordenador como sistema de comunicación virtual. Ahora bien, además de estas facilidades que ahora nos permite Internet, también debemos destacar que este sistema nos concede la opción de utilizarlo como herramienta para llevar a cabo actos de comunicación y notificar cuestiones personales o de trabajo, y también como un sistema por el que la Administración podría relacionarse con los particulares». 
la seguridad de esas acciones. Podría adaptarse a las aplicaciones de software más comunes, como el sistema de mensajería electrónica elaborado en el marco de las normas X.400, que se perfilan como una serie de directrices que regulan el funcionamiento del correo electrónico en lo que se refiere a protocolos ${ }^{60}$.

Los detractores, sin embargo, entienden que el correo electrónico tradicional adolece de graves limitaciones para satisfacer las exigencias de integridad, seguridad y autenticidad del mensaje ${ }^{61}$. Cuando empresas terceras intermedian en el proceso de notificación, su carácter privado impide considerar sus declaraciones del carácter probatorio reforzado propio de los documentos públicos administrativos ${ }^{62}$. Asimismo, la heterogeneidad de las características de los servicios de Internet que se ofrecen puede entrańar el rechazo de la notificación por el propio servidor sin que nunca llegue a depositarse en el buzón del destinatario. A todo ello debe ańadirse el hecho de que muchos de esos servidores se ubican fuera del territorio del Estado y que las carencias técnicas del servidor obstaculizan el empleo de firma electrónica. Aun así, en este último caso, debe notarse que no siempre se exige la firma electrónica para acceder a la notificación ${ }^{63}$.

El acuse de recibo, generado con carácter automático tras la recepción de la notificación, permitiría acreditar la puesta a disposición de la notificación, lo que sirve para interrumpir el plazo de prescripción o, en su caso, estimar practicada la misma a efectos del cumplimiento del plazo máximo para notificar la resolución en los procedimientos ${ }^{64}$. Asimismo, a partir del momento en que la notificación se deposita en el buzón del correo electrónico comienza a computarse el plazo de diez días naturales para el acceso y, en consecuencia, se le considera notificada a la destinataria ${ }^{65}$. Al hilo de esta cuestión se han planteado no pocas objeciones a la viabilidad de este sistema debido a la diversidad de sistemas de correo electrónico, lo que afecta a la prueba de certeza y autenticidad de los mensajes ${ }^{66}$. No obstante, ya se ha comentado que el protocolo X.400 permite la constancia automática de que el mensaje ha sido

60 Manteca Valdelande (2008, III).

61 Valero Torrijos (2007: 152). Asimismo, C. Barrero Rodríguez (2016), «La notificación de los actos administrativos», en F. López Menudo (dir.), Innovaciones..., cit., pág. 163.

62 Martín Delgado (2017: 2172 y 2173).

63 Menéndez Sebastián (2016: 34).

64 A. Palomar Olmeda (2007), La actividad administrativa efectuada por medios electrónicos, Cizur Menor: Aranzadi, pág. 151. Véase también J. I. Moreno Fernández (2013), «Las notificaciones electrónicas obligatorias en materia tributaria», Impuestos 5, págs. 13 y ss.

65 Art. 43.2 LPAC.

66 M. J. García García (2008), «La obligación de resolver y el régimen de comunicaciones y notificaciones electrónicas», Cuadernos de Derecho Público, 33, págs. 135-140. 
depositado en el buzón de destino y también el momento en que el mensaje ha sido abierto, para lo cual remite a los interesados las correspondientes notificaciones de entrega y acuses de recibo, que serán incorporadas al expediente administrativo como prueba válida de que la notificación ha sido practicada ${ }^{67}$. Aun así, no parece del todo concluyente la regulación operada por la LPAC.

\section{LA LEY 39/2015, DE 1 DE OCTUBRE, DEL PROCEDIMIENTO ADMINISTRATIVO COMÚN DE LAS ADMINISTRACIONES PÚBLICAS}

Las notificaciones por correo electrónico se omiten en la LPAC, permitiendo únicamente las que se practiquen en la sede electrónica por comparecencia o en la dirección electrónica habilitada única, o por ambos cauces. El art. $35 \mathrm{RAE}$, precepto que contemplaba la posibilidad de practicar notificaciones por correo electrónico, ha sido expresamente derogado por la disposición derogatoria $1^{\mathrm{a}} \mathrm{g}$ ) LPAC, por lo que, en teoría y de conformidad con la Ley de Procedimiento Administrativo, no pueden cursarse ni practicarse notificaciones a través de esta modalidad. Aun así, cabe la posibilidad de que el procedimiento se hubiera iniciado con anterioridad a la entrada en vigor de la LPAC, con lo que, si se trata de uno tramitado por vías telemáticas, todavía resultará de aplicación la normativa anterior, es decir, la LAE y su reglamento de desarrollo, que sí permitían el uso del correo electrónico siempre que se adecuase al cumplimiento de determinados requisitos.

La Ley incorpora el aviso de notificación que sí puede transmitirse por medio de correo electrónico, pero no puede equipararse a la notificación debidamente realizada. La auténtica novedad estriba en la implantación de herramientas tecnológicas que permitan verificar el acceso a este aviso por parte de la Administración, pues ello permite resolver si la persona interesada ha sido diligente o no para recibir la notificación y acceder a su contenido ${ }^{68}$. El problema que se suscita aquí no se deriva tanto de si el correo electrónico

67 Manteca Valdelande (2008, III) dispone de un mecanismo de alta fiabilidad para la actividad que hayan de desarrollar las administraciones públicas en sus relaciones con los ciudadanos. Asimismo, véase J. Calvo Vérgez (2009), «La realización de apoderamientos y de notificaciones tributarias y la interposición de recursos económico-administrativos a través de Internet», Gaceta Fiscal 288. Véase en www.gacetafiscal.com.

68 J. A. Santamaría Pastor y B. Lozano Cutanda (2016), «20 Cosas que todo abogado debe saber de la nueva Ley de Procedimiento Administrativo", Diario La Ley, 8851. Una interpretación integral y de conformidad con el art. 24 CE exige la obligatoriedad de publicación. 
sirve como medio para notificar fehacientemente, sino si puede considerarse un medio de prueba admitido en derecho para elaborar un relato fáctico que permita concluir que, más allá de que la Administración cumpliera adecuadamente sus cometidos formales, la persona interesada pudo acceder a la notificación sin un esfuerzo desmedido o desproporcionado ${ }^{69}$.

Al hilo de esta cuestión, se ha planteado la posibilidad de que subsista un error en torno a los datos del correo electrónico o, incluso, del teléfono móvil, de que dispone la Administración para efectuar el aviso. Incluso, el interesado puede haber cambiado los datos sobre este particular, lo que requeriría nuevamente que la persona interesada comunique los mismos a la Administración ${ }^{70}$. Sin embargo, no por ello debe excluirse la aplicación a estos casos de la doctrina del TC acerca de la diligencia y el celo que debe emplear la Administración para practicar la notificación, en tanto se halla en juego la tutela judicial efectiva ${ }^{71}$. En definitiva, el aviso por correo electrónico presenta una problemática no muy

69 Fernández Rodríguez (2015: 365). Asimismo, véase también L. Ruibal Pereira y F. Serrano Antón (2010), «Las notificaciones en la Ley General Tributaria», en J. Arrieta Martínez de Pisón, M. A. Collado Yurrita y J. Zornoza Pérez (dirs.), Tratado sobre la Ley General Tributaria, tomo II, Cizur Menor: Thomson Reuters-Aranzadi, págs. 399-406. STSJ Castilla y León (Burgos) 23 de mayo de 2014, RA JT/2014/1251, FD 7․ Además, el proceso de formateo comenzó con posterioridad a la notificación, aspecto este último que confirmó la versión del testigo presentado por la parte recurrente. Al haberse reiterado las averías por la antigüedad de los equipos, el Tribunal niega la posibilidad de que se exima de responsabilidad a aquella, puesto que debió renovar sus ordenadores. No debe aquí olvidarse que el art. 40 RD 1671/2009, de 6 de diciembre, obliga a las sociedades de capital a la notificación por medios electrónicos para todo lo referido a las liquidaciones tributarias que hubieran practicado. Se acordó, previamente, por tanto, incluir a la recurrente en el sistema de Dirección Electrónica Habilitada (DEH), así como la asignación de la misma, teniendo en cuenta que se trata de una entidad obligada a la tramitación de procedimientos electrónicos tributarios, con arreglo al art. 4 RD 1363/2010.

70 T. Cobo Olvera (2015), La notificación de los actos administrativos y disposiciones generales, Málaga: Fundación Asesores Locales, 2a edic., in toto.

71 SSTC 59/1998, FJ 30; 221/2003, FJ 4º; 55/2003, FJ 2o. STC 137/2014, FJ 4º. La autoridad judicial se limitó en ese caso a practicar la notificación en tan solo uno de los domicilios indicados, lo cual fue considerado como falta de diligencia por el TC. Véase un caso similar en STC 126/2014, FJ 4º. STC 126/2014, FJ 5º La dirección adecuada había sido empleada por el banco que pretendía ejecutar la hipoteca. Nuevamente le parece llamativo al TC, y lo es, el hecho de que, justo en el momento en que se procede a la ejecución, la notificación se practica en el domicilio real y correcto. De ahí que, pese a no haber comparecido en el proceso declarativo, posteriormente interpusieran recurso contra el acto de ejecución. 
diferente a la de la notificación, toda vez que permite acreditar el comportamiento leal, coherente y prudente de Administración y destinatario de la notificación, siempre que ese aviso pueda emplearse como prueba ante un tribunal ${ }^{72}$.

\section{ALGUNAS CUESTIONES CONTROVERTIDAS A LA LUZ DE LA SENTENCIA DEL TRIBUNAL SUPREMO DE 17 DE NOVIEMBRE DE 2016}

La sentencia resuelve el recurso de casación para la unificación de doctrina interpuesto contra la sentencia dictada por la Sala de lo ContenciosoAdministrativo de la Audiencia Nacional que, a su vez, desestimó el recurso interpuesto contra la Resolución de la Dirección General de Innovación y Competitividad de la Secretaría de Estado de Investigación, Desarrollo e Innovación del Ministerio de Economía y Competitividad, por la que se ordenaba el reintegro del préstamo, concedido por Resolución de 29 de diciembre de 2005, para la realización del proyecto denominado «Servicios de Telecomunicación, Seguridad y de Valor Añadido disponibles en el Parque CientíficoTecnológico del Olivar» ${ }^{73}$.

Se alegaba por la parte recurrente contradicción del fallo impugnado con las sentencias de la Sala de lo Contencioso del TSJ de Extremadura ${ }^{74}$, la Audiencia Nacional ${ }^{75}$ y la misma Sala de lo Contencioso del TS. El fondo de

72 L. A. de Diego Díez (2007), Garantías en la práctica de las notificaciones administrativas, Barcelona: Bosch, pág. 25.

73 STS 17 de noviembre de 2016, RA 6384.

74 STSJ Extremadura, de 4 de diciembre de 2012. Aunque se refiere a una jurisprudencia anterior, véase STSJ Extremadura, de 31 de marzo de 2015, JT/2015/857. Se trataba de un supuesto en el que la sociedad carecía de certificado electrónico para poder acceder a su dirección electrónica habilitada con carácter obligatorio para recibir notificaciones. Asimismo, tampoco figuraba ninguna persona o entidad con representación suficiente debidamente registrada en los sistemas informáticos de la Agencia Tributaria. Sin embargo, fue notificada a la dirección electrónica con acuse de recibo, sin que se agotaran los medios para localizar o practicar la notificación efectiva. El RD 1/2010, de 8 de marzo, obligaba a la Administración a la asignación correspondiente de la dirección electrónica a los obligados tributarios que así se considerasen por el RD mencionado. Dado que se acreditó el envío al domicilio social de la notificación por la que se le asignaba la dirección electrónica única, entonces debió haberse comunicado por medios electrónicos.

75 Si bien se refiere a la Sentencia de la Audiencia Nacional de 25 de noviembre de 2011, véase asimismo la SAN 19 de julio de 2016, JT/2016/1182. Se alega por la recurrente la infracción del deber de buena fe porque la Administración no recurrió a otros medios o mecanismos para intentar que la notificación llegase al conocimiento de la persona interesada. En concreto, se solicitaba la notificación por medios tradicionales, 
la cuestión giraba en torno a la posible prescripción de la potestad administrativa para exigir el reintegro de la ayuda prestada. Como es sabido, el plazo de prescripción de cuatro años se interrumpe mediante la notificación correcta de la Administración a la parte deudora, conforme al art. 39.1 de la Ley General de Subvenciones. La particularidad de este asunto estriba en que las comunicaciones que ejercían presuntamente el efecto de interrupción se efectuaron mediante correo electrónico, lo cual propició que la recurrente adujera defectos en las mencionadas notificaciones y, en consecuencia, no podían ser hábiles para interrumpir el plazo de prescripción.

Así, se alegaba por la recurrente que no constaba fecha cierta e indubitada en torno al momento en que se pudieron recibir los correos electrónicos, ni consentimiento expreso de la entidad para que se le notificase mediante correo electrónico. Además, uno de ellos no lo remitió directamente la Administración, sino una entidad privada. De este modo, se estimaba por la impugnante que otorgar validez a los citados correos electrónicos conllevaba una colisión frontal con diversas sentencias, no solo emanadas de tribunales superiores de justicia, sino también de la Sala de lo Contencioso de la Audiencia Nacional o del mismísimo TS. A continuación se abordan diferentes cuestiones que la sentencia examina, como la importancia del principio de buena fe, los efectos que despliega la notificación para la interrupción del plazo de prescripción, o la prevalencia del principio finalista sobre el formalista.

\subsection{El principio finalista prevalece sobre el formalista}

De los hechos que se consideran probados en la sentencia puede deducirse que un empleado de la empresa prestataria solicitó a la Administración mediante correo electrónico que se le enviara el informe correspondiente, debido a que no contaba con fax. Consta como elemento fáctico probado la fecha y la hora de recepción de dicho correo, con lo que el Tribunal de instancia declaró válida y eficaz la notificación practicada por este medio. Asimismo, el fallo señala textualmente que: «[...] Esta actuación llevada a cabo el 14 de julio

es decir, por acuse de recibo, con dos intentos y la correspondiente notificación edictal. La petición fue claramente rechazada porque, al disponer de dirección electrónica única para las notificaciones electrónicas en el ámbito tributario, carece de sentido aplicar la normativa propia de las notificaciones en papel. Al respecto, véase también SAN 7 de enero de 2016, JT/2016/96, FD 4º. Debe justificarse por la Administración que se estaba notificando fehacientemente al interesado la asignación de la Dirección Electrónica Habilitada Única. Al respecto, véase también STSJ Madrid 24 de junio de 2016, JUR/2016/186120, FD 4o. La notificación personal en este caso no fue correcta porque no se acreditó que pudiera ser recibida por la persona destinataria. 
de 2008 es un acto que interrumpe la prescripción, ya que va encaminada a verificar el cumplimiento de las condiciones de la ayuda y de ella puede surgir una obligación de reintegro, como de hecho sucedió» ${ }^{76}$.

La Sala consideraba probado que el interesado pidió expresamente que la notificación se efectuara por correo electrónico y, segundo, que la comunicación fue recibida por el destinatario. Respecto a la compatibilidad con la STS de 14 de octubre de 1996, la rechaza de plano, al dirimir una controversia que versaba sobre notificaciones practicadas por correo ordinario y no por correo electrónico, como se deriva del caso que ocupa.

Entre las conclusiones más llamativas se halla la ausencia de cualquier cuestionamiento en torno al correo electrónico como medio para la práctica de las notificaciones ${ }^{77}$. En ese sentido, se omite cualquier referencia o mención a la LAE o a la normativa actual, de modo que, no solo se prescinde del elemento formal que debe acompañar a cualquier notificación, sea o no electrónica, sino que ese hecho no ha sido fundamentado con arreglo al actual ordenamiento jurídico ${ }^{78}$. La argumentación del Tribunal a este respecto pivota en torno al principio antiformalista y, como se señalará posteriormente, a la buena fe. Los hechos determinantes de la actuación administrativa, como el envío de correos electrónicos, según los cuales, se asumen por el destinatario del acto ciertas consecuencias jurídicas, o la prueba practicada en la primera instancia, sirven como reemplazo o prácticamente inaplicación de la normativa aplicable ${ }^{79}$.

76 STS 17 de noviembre de 2016, RA 6384/2016, FD 6º.

77 Como ejemplo, STSJ Madrid, de 22 de septiembre de 2014, RJCA 2014/1008. En este caso se practicó una notificación por correo electrónico a la dirección de la empresa para requerirle de subsanación para un procedimiento consistente en la solicitud de inscripción en el Registro de Pre-asignación de retribución de instalaciones fotovoltaicas. En este caso, se obligaba por la norma reguladora del procedimiento (RD 1578/200) a mantener todas las comunicaciones entre el solicitante y el órgano instructor a través de correo electrónico. En consecuencia, debió accederse a la notificación por medios electrónicos. Se cita expresamente el art. 27 LAE y se examina si el uso obligatorio de la vía electrónica es o no proporcional.

78 No puede ignorarse la doctrina del TS en la materia, al insistir en que los requisitos formales permiten acreditar que se han empleado todos los medios a disposición de la Administración para practicar la notificación. Al respecto, véanse STS 16 de junio de 2014, RA 3667, FD 4º y 12 de diciembre de 1997, RA 2264, FD 7º, y en jurisprudencia del tribunales superiores se destaca la STSJ Madrid 11 de abril de 2014, RA JUR/2014/137336, FD 30.

79 O. Rodríguez Díaz (2001), «La práctica de las notificaciones administrativas, mediante correo: especial consideración a la sentencia del Tribunal Supremo de 12-12-1997 
Por otro lado, al tratarse de un fallo que examina un procedimiento sometido a la legislación previa, sea la LRJPAC o la LAE, lo cierto es que tampoco parece resultar de interés alguno para la autoridad judicial el principio de voluntariedad que, aun limitado por ciertas excepciones fijadas por Reglamento, se presenta como el eje que vertebra la Administración electrónica de acuerdo con la normativa anterior ${ }^{80}$. A su vez, causa cierta perplejidad que, atendiendo a algunas posibles excepciones a aquel principio de voluntariedad, como la obligatoriedad de relacionarse por vías electrónicas que recae sobre ciertos colectivos que reúnen determinadas características, la Sala sentenciadora soslaya la posibilidad de citar o referirse siquiera a una normativa sectorial, aunque sea de rango reglamentario, que justificase el empleo del correo electrónico como medio de comunicación y notificación ${ }^{81}$.

Una posterior notificación se llevó a cabo mediante una entidad privada que actúa en el marco de un contrato, por el que realiza una prestación de seguimiento de las actividades objeto de subvención, que le corresponde a la Administración y por cuenta de esta. Pese a que no había constancia física de la recepción del correo electrónico, en el informe técnico-científico de la entidad se señalaba que la entidad remitió la información. El Tribunal permite deducir de todo ello que «la comunicación llegó a su destinatario, surtiendo efecto». A continuación el fallo se inclina de forma palmaria por otorgar prioridad a la finalidad de dar a conocer el contenido de un acto más allá de las formalidades o cauces empleados para ello. La formalidad, en consecuencia, "[...] no puede convertirse en un fin en sí mismo, cuando podemos comprobar por otros medios que la comunicación se produjo y llegó al beneficiario» ${ }^{82}$.

Para corroborar esa afirmación se citan algunas sentencias del TS y se concluye de forma categórica que la comunicación fue regular y, en consecuencia, debió suponer la interrupción de la prescripción. Estos pronunciamientos a los que se hace alusión expresa muestran, sin embargo, parte de la

y su incidencia tras la reforma de la Ley 30/92 y la reforma de la Ley de Servicios Postales», Revista Jurídica de Castilla-La Mancha, 31, pág. 302. Asimismo, véase H. Hernández Jiménez (2013), «El lugar para la práctica de las notificaciones», Actualidad Administrativa, 12, véase en www.laley.es.

80 STSJ Extremadura 4 de diciembre de 2012, JUR/2013/7293, FD 2º. En el expediente no constaba la solicitud del interesado para la utilización del fax como medio para recibir notificaciones por la Administración. Se trataba de una sanción y fue anulada, con retroacción de actuaciones, por entenderse que la notificación no era válida.

81 Como así sucede, por ejemplo, en la STSJ Extremadura de 31 de marzo de 2015, JT/2015/857, FD 4º, ya mencionada anteriormente, o la SAN 19 de julio de 2016, JT/2016/1182, también citada con anterioridad.

82 STS 17 de noviembre de 2016, cit., FD 6º. 
abundante casuística y enormemente heterogénea jurisprudencia en torno a esta materia ${ }^{83}$. Si bien muchas sentencias del TS no se referían a las comunicaciones por correo electrónico, no puede aseverarse con rigor que el criterio formalista se ha abandonado a su suerte por la jurisprudencia de la Sala $3^{\text {a }}$. Más bien, los requisitos formales se presentan como elementos destinados a garantizar la finalidad de las notificaciones, cual es el conocimiento del contenido del acto por el destinatario. Todo ello significa que no pueden ser ignorados porque contribuyen al reconocimiento y ejercicio efectivo de las garantías procesales que conllevan las notificaciones. Así, la ausencia de firma en la cartulina rosa; la omisión del número de documento nacional de identidad; la falta de una somera referencia al contenido del acto o, incluso, no señalar la causa del rechazo de la notificación se han considerado motivos suficientes para invalidarla por defectos formales ${ }^{84}$. En definitiva, no siempre prevalece el elemento finalista o funcional de la notificación, sobre todo si de los hechos no puede desprenderse de forma palmaria que ha habido un conocimiento pleno de la notificación, más allá del componente técnico inherente a las comunicaciones electrónicas ${ }^{85}$.

\subsection{El principio de buena fe}

La lealtad a la palabra dada; la actuación de acuerdo con una actitud diligente, y la honestidad y coherencia mostrada entre aquello a lo que se compromete una persona y su actuación en la realidad de los hechos ${ }^{86}$, todas estas expresiones pueden resumir muy brevemente el significado del principio

83 Sin ir más lejos, esta afirmación debe contrastarse con otras que recoge el TC en diferentes casos y que apuntan al hecho de que, aun siendo medios, las formalidades tienden a garantizar la tutela judicial efectiva por la recepción de la notificación. Véanse al respecto, STC 150/2016, FJ 3º; STC 126/2014, FJ 5º. La dirección adecuada había sido empleada por el banco que pretendía ejecutar la hipoteca. STC 137/2014, FJ 4º. La autoridad judicial se limitó en ese caso a practicar la notificación en tan solo uno de los domicilios indicados, lo cual fue considerado como falta de diligencia por el TC. Véase un caso similar en STC 126/2014, FJ 4º. Y los precedentes más remotos en las SSTC $158 / 2001$, FJ $5^{\circ}$ y $216 / 2002$, FJ $4^{\circ}$.

SSTS 27 de enero de 2009, RA 859, FD 50 y 21 de enero de 2010, RA 3081, FD 3º. Si el obligado tributario cumple con la carga de comunicar el domicilio, ese nuevo domicilio no es oponible ante la Administración, siempre que esta última hubiera actuado con diligencia y buena fe.

85 Ruibal Pereira (2007: 694).

86 J. González Pérez (2009), El principio general de la buena fe en el Derecho Administrativo, Cizur Menor: Thomson-Reuters, Civitas, pág. 43. 
de buena fe, que está cobrando una especial relevancia en materia de notificaciones $^{87}$. La realización de actuaciones por parte del interesado puede dar a entender que conocía el contenido de un acto y, en consecuencia, pese a que no se cumplieron las formalidades inherentes a la práctica de la notificación, esta puede desplegar de igual forma sus efectos ${ }^{88}$. $\mathrm{Al}$ respecto, el artículo 40.3 LPAC, tal y como lo expresara la LRJPAC, recoge de forma algo escueta esta tesis que, de todos modos, se presta a no pocas interpretaciones que deben resolverse en sede probatoria y con arreglo a presunciones, es decir, requieren una resolución caso por caso ${ }^{89}$.

En el fallo que se comenta se señala expresamente que el debate radica en decidir si la facultad de la Administración para ordenar el reintegro del anticipo reembolsable estaba o no prescrita. En consecuencia, de las comunicaciones que efectúa la Administración debería desprenderse con toda claridad la exigencia del pago o reintegro de la subvención, pues, de lo contrario, se omite el contenido del acto o el texto de la resolución, en palabras de la LPAC, y el principio de buena fe decae irremisiblemente ${ }^{90}$. En otras palabras, si la Administración no ha expresado con claridad meridiana su decisión o voluntad, resulta en extremo complicado que las actuaciones posteriores de la persona destinataria puedan coincidir o ser congruentes con ella ${ }^{91}$. Se analizan ambos correos electrónicos y así podrán inferirse algunas conclusiones.

En el primer correo electrónico, la empresa beneficiaria solicitó a la Administración la remisión del informe a través de este medio, según el cual, se remitía la ficha de control de gastos ${ }^{92}$. Al respecto, la Ley de Subvenciones

87 C. García Novoa (2001), Las notificaciones tributarias, Aranzadi, Elcano, pág. 91.

88 Cuadrado Zuloaga, D. (2004), «Las notificaciones administrativas por correo», Actualidad Administrativa, 13, véase en www.laley.es.

89 M. M. Jiménez Navas (2009), Régimen jurídico de las notificaciones en el ámbito tributario, Tesis Doctoral dirigida por A. M. Cubero Truyo, Universidad de Sevilla, págs. $15-17$.

90 STS 26 de mayo de 2014, RA 2828, FD 5º.

91 Gallardo Castillo (2016: 150 y 151).

92 SAN 14 de enero de 2016, JUR/2016/28103, FD 2º. Asimismo, De Diego Díez (2007: 101). Velasco Caballero entiende cumplido el requisito de eficacia del acto desde el momento en que la Administración, aun habiendo notificado incorrectamente en cuanto a la información acerca de los recursos, sí ha comunicado el texto íntegro del acto. No significa que se subsane por ese hecho la notificación no válida, sino que el legislador ahí establece un sistema de eficacia basado en presunciones que prescinde del dato de la validez del acto en sí. En F. Velasco Caballero (2002), «Notificaciones administrativas: presunciones y ficciones», Justicia Administrativa: Revista de Derecho Administrativo, 16, pág. 41. Asimismo, véase J. Oliván del Cacho (2000), «Precisiones 
establece, como causas de interrupción de la prescripción, la «acción de la Administración, realizada con conocimiento formal del beneficiario o la entidad colaboradora, conducente a determinar la existencia de alguna de las causas de reintegro»" ${ }^{33}$. Para acreditar la buena fe en este caso se precisaría dar a conocer exactamente el contenido de esa ficha de gastos y si realmente de la misma puede entenderse la existencia de una deuda y su alcance ${ }^{94}$. Piénsese que la misma sentencia, al igual que la de instancia, no consideró probado el envío de la posterior notificación emitida por la entidad privada supervisora o colaboradora. Por tanto, cabe interrogarse respecto a la eficacia de una comunicación que se limita a exponer los gastos sin precisar exactamente la causa del reintegro. La sentencia de instancia declara que se interrumpe la prescripción «ya que va encaminada a verificar el cumplimiento de las condiciones de la ayuda, y de ella puede surgir una obligación de reintegro, como de hecho sucedió». Determinar las causas del reintegro se equipara a verificar el cumplimiento de las condiciones de la ayuda, pese a que parecen hechos distintos y, en consecuencia, pueden ocasionar cierta inseguridad jurídica. Así, del informe puede deducirse que no es necesario abonar reintegro alguno. Para entender interrumpida la prescripción, debería haberse notificado el desglose completo de gastos y, en consecuencia, el saldo positivo o negativo.

Respecto al segundo correo electrónico, la entidad privada colaboradora de la Administración llevó a cabo una nueva comunicación que conllevaba la interrupción del plazo de prescripción, al efectuar el correspondiente seguimiento. No obstante, no queda constancia física de la recepción de ese correo, si bien la beneficiaria le remitió información, de lo que puede deducirse, a tenor del Tribunal, que la comunicación llegó a su destinatario, surtiendo efecto $^{95}$. En este caso, pese a que ni siquiera ha quedado constancia de la comunicación, la actividad de la entidad subvencionada permite deducir que

sobre la convalidación de las notificaciones (Acerca de una previsión de la Ley 4/1999 contradictoria con su Exposición de Motivos)», Cuadernos de Derecho Público, 9, págs. 204-210.

93 Art. 39.3 a) Ley 38/2003, de 17 de noviembre, de Subvenciones.

94 Puede citarse al respecto la SAN 7 de enero de 2016, JT/2016/96, FD 4º. En este caso, se demostró que, en efecto, la sociedad notificada había accedido al contenido de los correos electrónicos, pero el Tribunal entiende que, al no acreditarse fehacientemente la notificación por la que se le asignaba la dirección electrónica única, le resultó imposible recibir las notificaciones precedentes que se efectúan por correo electrónico. Aquí el Tribunal tampoco pone reparos en cuanto a la posibilidad de que, mediante una simple prueba, la Administración pudo acreditar la notificación por correo electrónico.

95 STS 17 de noviembre de 2016, cit., FD 60. 
conoció el contenido del acto. Este segundo supuesto no se ajusta, siquiera en una interpretación forzada, a la Ley de Subvenciones, porque la conducta del beneficiario no iba dirigida a la liquidación de la subvención o al reintegro, sino a la entrega de un informe.

La contradicción que podría subyacer respecto a las sentencias mencionadas anteriormente fue rechazada por la Sala $3^{\text {a }}$ del TS, al entender que aquella jurisprudencia no concluyó que la notificación efectuada por una entidad privada tiene virtualidad para interrumpir la prescripción, sino que lo que permite interrumpir la prescripción es el hecho de que la entidad destinataria de la subvención responda, puesto que conlleva «cualquier actuación del sujeto pasivo conducente al pago o liquidación de la deuda ${ }^{96}$, tal y como, por otra parte, se desprende de la legislación tributaria. Así, el problema de fondo estriba en el «[...] valor que tiene a estos efectos la contestación dada por la entidad subvencionada como posible actuación conducente al pago o liquidación de la deuda». De esta forma, no adquiere relevancia alguna la actividad administrativa, tendente a cumplir unas formalidades que otorguen garantías de defensa y de seguridad jurídica a los interesados, pese a que recae sobre ella el deber de emplear todos los medios a su disposición para cerciorarse de que la persona destinataria conoce el contenido del acto ${ }^{97}$.

En cualquier caso, como se aprecia, el Tribunal no aporta un argumento de suficiente solidez jurídica como para apoyar el uso del correo electrónico a través de una notificación, de manera que esquiva el debate principal para rechazar la casación de la sentencia, al no apreciar la identidad de objeto y hechos entre los fallos presuntamente divergentes. Es la sentencia de instancia la que expone los argumentos favorables al uso del correo electrónico y que fundamentan la aplicación de la LAE en su artículo 27.

\subsection{El uso del correo electrónico como medio de notificación}

A diferencia de la sentencia de casación, la sentencia de instancia fundamentó su fallo en la LAE. En concreto, citó el artículo 27 de la misma, referida a las comunicaciones electrónicas, si bien su análisis en cierto sentido

96 Ibid., FD 70

97 Tal y como puede desprenderse de la jurisprudencia del TC el TS y cierta doctrina, recae sobre la Administración la carga de la prueba en torno a la práctica de la notificación, insistiendo en la necesidad de guardar el máximo celo para garantizar su recepción. Al respecto, véanse SSTC 219/1999, 128/2000, 13/2001 y 19/2004. Asimismo, no puede ignorarse la STS 24 de mayo de 1993, RA 3503, FD 2º. Acerca de esta cuestión y a favor de que recaiga la carga de la prueba sobre la Administración, véase De Diego Díez (2007: 31). 
puede calificarse como algo sesgado. En efecto, por un lado, el apartado tercero del precepto mencionado señala que las comunicaciones a través de medios electrónicos serán válidas siempre que exista constancia de la transmisión y recepción, de sus fechas, del contenido íntegro de las comunicaciones y se identifique fidedignamente al remitente y al destinatario de las mismas ${ }^{98}$. A continuación, de la prueba presentada deduce, como ya se ha recogido anteriormente, que el propio interesado solicitó el envío por correo electrónico y se acreditó «el envío, la petición y el día y hora de llegada», con lo que sostuvo que la notificación era válida y eficaz.

Se suscita al hilo de esta cuestión un debate de amplias dimensiones en esta materia. En vía judicial se logró acreditar la existencia del correo electrónico, su emisión y la recepción. Ahora bien, ¿todos estos elementos son suficientes para que esa comunicación resulte válida y eficaz, teniendo en cuenta que se transmite por vía electrónica? La LAE ya preveía que los certificados electrónicos reconocidos emitidos por prestadores de servicios de certificación serán admitidos por las administraciones públicas como válidos para relacionarse son las mismas, siempre y cuando el prestador del servicio de certificación ponga a disposición de las administraciones públicas la información que sea precisa en condiciones que resulten tecnológicamente viables y sin que suponga coste alguno para ellas ${ }^{99}$. La actual Ley de Procedimiento, asimismo, dispone que las administraciones públicas están obligadas a verificar la identidad de los interesados en el procedimiento administrativo y para ello han de emplear sistemas que permitan garantizarla ${ }^{100}$.

Estos mecanismos permiten garantizar la autenticación, es decir, asegurar que el documento electrónico pertenece o procede del emisor y que el receptor lo recibe en las mismas condiciones ${ }^{101}$. A todo ello deben añadirse

98 SAN 14 de enero de 2016, JUR 2016/28103, FD 2º. Se limita a citar el apartado 3 del art. 27 LAE, y afirma que se acredita el envío, la petición, el día y la hora de llegada, con lo que la notificación es válida y eficaz. Aun así, no examina con detenimiento y rigor técnico si, en efecto, el correo electrónico puede en esas circunstancias servir como medio para practicar notificaciones electrónicas. Esto puede servir como un peligroso precedente que justifique, incluso, que por la vía reglamentaria se autorice el uso del correo electrónico, sin acreditar que sus herramientas permitan tener constancia y fehaciencia de todas las comunicaciones, su autenticidad, la puesta a disposición y el acceso.

99 Art. 21.1 LAE.

100 Art. 9.1 y 2 LPAC.

101 J. Brines Almiñana (2008), «Análisis de la Ley 11/2007, de 22 de junio, de Acceso Electrónico de los Ciudadanos a los Servicios Públicos: retos y desafíos en el ámbito local», Diario La Ley, 7036, 17 de octubre de 2008, ref. D-294. 
los sistemas de seguridad que impidan cualquier distorsión o deficiencia en la comunicación, además del deber de alcanzar la interoperabilidad de todos ellos $^{102}$. Pues bien, si se emplea como fundamento el mencionado artículo 27 sobre comunicaciones electrónicas, además de aplicar las garantías propias del consentimiento y la voluntariedad, también debe examinarse si la actividad administrativa se ajustaba a estas exigencias inherentes a las comunicaciones electrónicas. Se precisa que la persona interesada y la Administración sean identificadas de forma fidedigna ${ }^{103}$.

Sirva como prueba de lo que se comenta la grave omisión en que incurren ambas sentencias al referirse exclusivamente al envío y recepción del mensaje, no tanto al acceso al mismo. Llama la atención que se ignore la aplicación del artículo $20 \mathrm{LAE}$, en tanto que contempla claramente las cuatro fases básicas en una comunicación electrónica, cuya constancia debe quedar reflejada, bien sea a través de plataformas electrónicas, bien mediante el correspondiente software cuales son la emisión, la recepción y almacenamiento del mensaje, además del acceso al mismo por parte de la persona destinataria. Solicitar el envío por correo electrónico de determinada información no comporta de manera tautológica el acceso al mismo. Para acreditar que se ha conocido la comunicación, debe disponerse de otras herramientas que, o bien no se mencionan, o bien, existiendo, no han sido evaluadas y enjuiciadas para decidir si la notificación era o no válida y eficaz.

En la actualidad, la Ley de Procedimiento no permite la notificación electrónica efectuada mediante correo electrónico, sino que requiere la comparecencia en la sede electrónica o el acceso a través de la dirección electrónica habilitada única (o ambas), puesto que para ello la persona interesada o su representante han debido acceder mediante claves o medios seguros de identificación ${ }^{104}$. Además, las notificaciones se entienden practicadas en el momento

102 M. A. Davara Rodríguez (2015), «La Administración electrónica: paradigma de una Administración moderna eficiente y eficaz», Actualidad Administrativa, 6, véase en www.laley.es. Asimismo, véase Martín Delgado (2017: 2175). Según el autor: «[...] No toda tecnología es válida en el ámbito del Derecho Administrativo, sino que el juego de las garantías del procedimiento conlleva la exclusión de determinados medios de notificación».

103 Art. 27.3 LAE. Véase Cotino Hueso (2010: 231) y Valero Torrijos (2010: 367).

104 SSTSJ 25 de febrero de 2016, JT/2016/685, FD 50 y 18 de febrero de 2015, JT/2015/731, FD 4o y 5 de mayo de 2015, JUR/2015/156734, FD 5. La cuestión se centra nuevamente en el hecho de que el RD 1363/2010, de 29 de octubre, en materia tributaria obligaba a comunicarse a determinados sujetos con la Administración tributaria por vías electrónicas. La cuestión es que no se admite tampoco como cauce de comunicación el correo electrónico, sino la dirección electrónica habilitada única, 
en que se produzca el acceso a su contenido o por el transcurso de diez días naturales desde la puesta a disposición sin que se haya accedido ${ }^{105}$. Podría entenderse que la LAE distinguía entre la comunicación y la notificación propiamente, de modo que aquella, por ejemplo, no comportaba la necesidad de acreditar el acceso a la misma. No obstante, tal tesis no se aviene a las garantías procesales y al principio de seguridad jurídica, sobre todo si no se distingue en qué supuestos procede la comunicación y en cuáles la notificación.

\section{CONCLUSIONES}

Primera. Se incurre en un error al pensar que una comunicación electrónica debe ajustarse estrictamente a los postulados y presupuestos de las notificaciones en papel. La razón estriba en que los cauces a través de los que se transmite la información son diferentes y, en consecuencia, las formalidades y requisitos que han de cumplir unas y otras también presentan diferencias. Eso no significa que ambas no deban inspirarse en los principios y reglas básicas en materia de notificaciones, como el empleo de todos los medios a disposición de la Administración para que el destinatario conozca el acto.

Segunda. El correo electrónico podría admitirse como medio de notificación, siempre que esta herramienta reúna las condiciones técnicas indispensables para garantizar la interoperabilidad, la seguridad y la autenticidad de las comunicaciones, más allá de que una ley sectorial incorpore este mecanismo notificador. La razón estriba en que no pueden soslayarse las garantías de defensa y de seguridad jurídica que amparan a cualquier persona que entabla relación con la Administración pública. Si bien las formalidades o los medios para notificar pueden revestir una importancia relativa de acuerdo con el principio de buena fe, se presentan como condición necesaria, instrumento clave para que la notificación, lejos de ser un mero trámite, se perfile como uno de los ejes que vertebran las garantías procesales.

Tercera. Sustentar el debate en torno a la notificación en las actuaciones o presunciones de los hechos y comportamientos de Administración e interesado entraña un riesgo de considerables dimensiones si se pretende evitar la indefensión o la inseguridad jurídica. La más mínima duda respecto a la recepción o conocimiento de un acto administrativo conlleva dejar inerme a la ciudadanía frente al inmenso poder de la Administración. Así, contestar

que, en efecto, ha de ser notificada fehacientemente al sujeto obligado por parte de la Administración.

105 Art. 43.1 y 2 LPAC. 
o no un correo electrónico o enviar por ese medio determinada información puede servir como un elemento más a tener en cuenta para decidir si la notificación es o no válida. Sin embargo, no puede ser suficiente, de forma que las administraciones han de observar un severo celo en la implantación de los medios necesarios para cerciorarse de que el interesado ha accedido - $\mathrm{O}$ en su caso ha podido acceder- a la notificación, siempre respetando los requisitos legales y reglamentarios.

Cuarta. La reciente sentencia del Tribunal Supremo de 17 de noviembre de 2016 comete el error de no examinar una comunicación electrónica partiendo de los postulados, exigencias o formalidades inherentes a las mismas. Introduce un peligroso precedente en esta materia, al primar el resultado de la prueba que se practica en el proceso correspondiente sobre la estricta aplicación de la legalidad, que consiste en comprobar si realmente concurren las garantías técnicas para acreditar la recepción del mensaje. Si bien la sentencia otorga cierta relevancia a los hechos (principio de buena fe), no puede desdeñar el derecho, ignorando de manera palmaria categorías y formas cuyo fundamento gira en torno a la persona y sus derechos. 
